https://doi.org/10.48009/1_iis_2007_84-90

\title{
INTEGRATING ERP ACROSS THE CURRICULUM: A PHASED, THREE-TIERED APPROACH
}

\author{
Mark C. Springer, Western Washington University, mark.springer@wwu.edu \\ Steven C. Ross, Western Washington University, steve.ross@wwu.edu \\ Nate Humann, Western Washington University, nate.humann@wwu.edu
}

\begin{abstract}
The authors propose a phased, three-tiered approach for incorporating enterprise system software into the curriculum. The courses in each tier have different objectives and requirements. By phasing in the tiers over time, maximum student exposure and minimal course disruption is achieved. The authors illustrate this approach by discussing the on-going implementation of SAP R/3 into the curriculum at one university.
\end{abstract}

Keywords: Enterprise Resource Planning (ERP), Curriculum

\section{INTRODUCTION}

The use of commercial enterprise resource planning (ERP) software in the classroom has been advocated by academics as well as software vendors and their corporate customers for several years [1] [2]. In the surge of ERP implementations leading up to the current millennium, a dearth of experienced ERP users led certain ERP vendors to provide their software to universities for classroom use, with the expectation that student exposure to current ERP software would both increase students' marketability and enable faculty to teach concepts and topics in a more effective manner.

SAP, the market leader in large-scale enterprise software, has devoted significant resources to forming the SAP University Alliance Program [3]. Formed in 1996, the Alliance makes SAP software available to universities for a nominal fee. However, while the program has gone through several iterations aimed at facilitating university involvement, joining the Alliance is not a casual matter. The application process makes it quite clear that SAP is interested in partnering only with universities willing to make a significant commitment to integrating $\mathrm{R} / 3$ into the curriculum [9][10].

While the start-up costs associated with introducing enterprise software into the curriculum remain significant, we propose an approach which requires minimal initial faculty investment, yet quickly exposes large numbers of students to ERP. We feel strongly that a school's ERP initiative should not be relegated to a single course or discipline, but should reinforce the enterprise-wide and cross-functional nature of enterprise software. We therefore have adopted an approach which emphasizes breadth as well as depth: three "tiers" of differing learning objectives are identified across the curriculum, and development of curriculum at each tier may be easily introduced over time rather than in a "big bang" approach which is difficult to fund and implement.

\section{ENTERPRISE SOFTWARE IN THE CURRRICLUM}

Recent studies have shown that a significant number of universities have made progress towards introducing enterprise software into the curriculum. Based on responses from 107 AACSB-accredited schools, Willems and Bhuiyan [11] discovered that over one quarter of the respondents were currently using enterprise software in the curriculum; another $15 \%$ were planning on introducing ERP within the next five years. Of those universities that had successful implementations, Willems and Bhuiyan were encouraged that only $20 \%$ found the implementation to be "extremely difficult."

Hayen and Andera [4] summarized the results of fifty-two published ERP-oriented curriculum initiatives. Slightly more than half of the cases examined involved only a single course; that is, use of the enterprise software was concentrated in a single course rather than being distributed across the curriculum. This result confirmed an earlier survey, conducted by the same authors, of SAP University Alliance members. In that survey, the authors concluded based on thirty responding institutions that "the most frequently reported effort is a single course" [5]. Similarly, an investigation of ERP offerings by SAP University Alliance members by MacKinnon and MacKinnon [6] found that the modal number of such courses offered at the undergraduate or graduate level was one-assuming that the university was offering any courses utilizing enterprise software. 
Taken together, these studies suggest that, while there are an increasing number of universities attempting to use enterprise software in the curriculum, many of these efforts are currently represented by a small cadre of faculty members (or a single faculty member) teaching "the ERP course." The relegation of ERP to an isolated course is somewhat ironic, since enterprise software is designed to facilitate cross-functional integration. Ideally-and this indeed remains an objective of SAP University Alliance representatives as well as academiciansstudents would be exposed to enterprise software in different functional contexts, thereby reinforcing the concept that enterprise software is not an IT or supply chain tool, but an enterprise-wide tool.

\section{PRACTICAL CONSTRAINTS AND LIMITATIONS}

The practical reasons for teaching ERP in a small number of dedicated courses are obvious: learning the software and developing curriculum geared to an existing functional course can be extremely time consuming, and it is more "efficient" to have one or two dedicated faculty members become the "subject matter experts" for the whole business school. While there are certainly examples of a university undertaking a major ERP initiative with a substantial commitment by the administration [3][7], a more likely scenario is that of a "lone ranger" who pursues enterprise software curriculum integration on his or her own initiative.

The unfortunate result of the "lone ranger" approach is that ERP becomes, in the student mind, an "MIS course" or an "OPS course" depending on where it is housed. While it may be necessary to have a dedicated ERP course for more advanced topicssuch as enterprise system configuration-students without an MIS or operations focus may graduate without a proper understanding of the impact of ERP on the organization. We contend that a welldesigned multi-tiered approach, with different ERP course learning objectives at each tier, better addresses student needs without requiring significant additional resources beyond the "lone-ranger" approach.

\section{A THREE-TIERED APPROACH}

Our basic approach is outlined in Figure 1: expose all students to ERP fundamentals from the perspective of different functional areas (Tier I); provide in-depth knowledge of enterprise systems for each student within his or her selected functional area (Tier II); and, for those students with greater interest in enterprise systems, a capstone ERP course which focuses on cross-functional integration (Tier III).

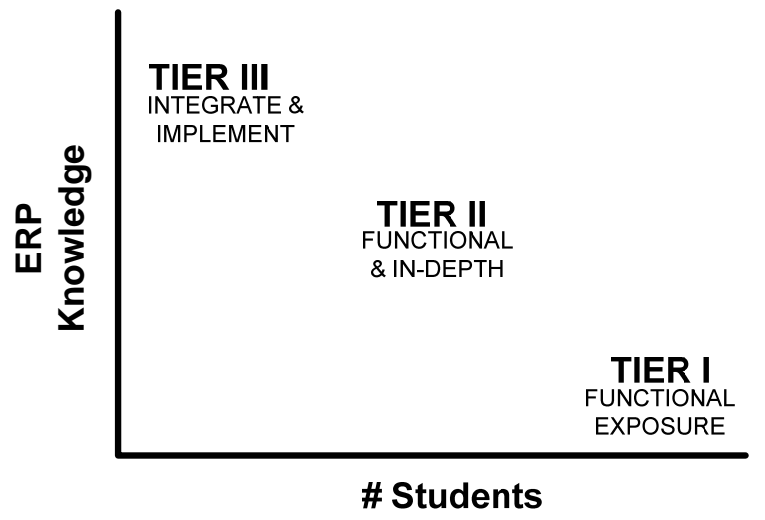

Figure 1. The Three Tiers of ERP-Impacted Courses

The courses in each Tier have different requirements and characteristics, as we discuss below and as is illustrated in Table 1.

Table 1. Characteristics of Courses in Each Tier

\begin{tabular}{|l|l|l|l|}
\hline \multicolumn{1}{|c|}{ Property } & \multicolumn{1}{c|}{ Tier I } & \multicolumn{1}{c|}{ Tier II } & \multicolumn{1}{c|}{ Tier III } \\
\hline $\begin{array}{l}\text { Knowledge } \\
\text { Objective }\end{array}$ & Exposure & In-Depth & Integrative \\
\hline $\begin{array}{l}\text { Course } \\
\text { Level }\end{array}$ & $\begin{array}{l}\text { Intro- } \\
\text { ductory }\end{array}$ & Advanced & Advanced \\
\hline $\begin{array}{l}\text { Course } \\
\text { Type }\end{array}$ & $\begin{array}{l}\text { Func- } \\
\text { tional }\end{array}$ & Functional & $\begin{array}{l}\text { Cross- } \\
\text { Functional }\end{array}$ \\
\hline $\begin{array}{l}\text { Lab } \\
\text { Content } \\
\text { (a \% of } \\
\text { course) }\end{array}$ & $5-10 \%$ & $10-50 \%$ & $75-100 \%$ \\
\hline Lab Type & $\begin{array}{l}\text { Display } \\
\text { Only }\end{array}$ & $\begin{array}{l}\text { Master Data, } \\
\text { Transactions }\end{array}$ & Configure \\
\hline
\end{tabular}

\section{Creating Robust Labs at Tier I}

Students' first exposure to ERP is in the introductory courses at Tier I. These courses are typically taught at the sophomore and junior level and have titles such as "Introduction to Managerial Accounting" and "Principles of MIS." In most business curricula, these classes are required of all business students. Ideally, this tier would include a course from each functional area, although full achievement of this goal may not be immediately reachable and is not necessary for a successful program. It is preferable, however, that at least two or three courses be included at Tier I to ensure that students gain exposure to ERP within the context of different functional areas.

Courses in this tier tend to be rather large, and instructors frequently feel pressed for time to cover the necessary material. ERP labs designed for these 
courses should therefore be short, stand-alone exercises that complement the course by highlighting a real-world application of the course material. The labs could be demonstrated by the instructor in front of the class, or, ideally, performed individually by students in a computer lab. We have found that a single two-hour lab works well at this tier.

Since students will not have much experience navigating the ERP interface, and to make the labs run smoothly in the limited time allotted, labs at this tier should be display-only. As users of enterprise systems will be aware, there is no "undo" in accounting-based enterprise systems, and in a large student lab with limited tech support it is important to minimize the chance of students getting off-track. To enable students to trace the flow of transactions, transactions can be entered prior to the lab by an instructor, and the lab documentation can then allow students to navigate through the transactions and related master data. This allows students to effectively "simulate" performing the transactions, and allows them to cover an entire business process (e.g., the sales order process) in a single two-hour session.

Because there is relatively little that can go wrong when students are merely displaying records, the instructor does not require expertise in system diagnosis to direct the lab. The instructor can instead focus on how the lab illustrates the concepts and tools discussed in the class.

A further benefit of designing "robust" labs at Tier I is that it enables multiple classes to use the same client; each client is a self-contained unit which contains its own master records and data tables. SAP, like many ERP vendors, restricts its University Alliance members to five simultaneous clients, with the intention that each client will be used by a single class. This makes sense if classes are adding and editing data, as it protects data from one class from being disrupted by another class. If classes are restricted to display-only access at Tier I, however, several classes could be working off of the same client in the same academic quarter or semester. Hundreds of students could thus be exposed to ERP with the use of a single client.

\section{Focus and Support at Tier II}

Tier II courses are upper-level courses where an ERP lab is useful for illustrating a practical application of the concepts and tools being covered in the course. These courses are typically restricted to students in a particular major, therefore most students would take only one or two of the Tier II courses as part of their business studies. At Tier II, a further distinction exists between "core" courses, namely those classes for which enterprise systems are integral to the course's central concepts and tools, and those for which it is not. "Core" Tier II classes study information systems-dependent topics in the different disciplines; obvious candidates would be an accounting information systems course or an operations planning and control course. Students would gain specific, in-depth knowledge of those ERP components related to the course. Rather than being restricted to display-mode as in a Tier I course, students would be entering master data and performing business processes (executing transactions).

“Core” Tier II courses require a greater investment of faculty learning time than Tier I courses because students are entering data and a large fraction of the class is lab-oriented. Instructors must understand the software elements well enough to diagnose student issues. "Non-core" Tier II courses are similar in the level of lab ERP work required, but have less of an ERP lab component and are therefore easier to set up. For example, an advanced course on forecasting may simply need a couple days of lab time to illustrate selected forecasting capabilities within an enterprise system. ERP lab content for Tier II courses is therefore likely to run from $10 \%$ to $50 \%$ of the course, the latter being possible for the more intensive Tier II courses.

\section{Pulling It All Together at Tier III}

At Tier III, students will focus on the cross-functional and integrative nature of ERP; this is the level at which the "real" ERP course is taught. To enroll in a course at this level, students will have taken all of the Tier I ERP courses and at least one of the core Tier II courses. Students will therefore have broad introductory experience to the enterprise system in use at their school, and in-depth knowledge of the system from the vantage of their chosen functional area.

The most obvious candidate for a Tier III course is a system configuration course. After entering transactions in a previously configured system in their other courses, students will now start with a blank client and configure the client for each of the functional areas. The lab component, which will be substantial in this course, can be complemented with studies focused on implementation and integration issues. 
This course clearly requires the most instructor preparation and ERP savvy, as the opportunities for students to stray from the laboratory script will be legion and possibly difficult to diagnose. The instructor for this course would typically have a research or consulting interest in ERP systems.

\section{IMPLEMENTATION ISSUES}

Having identified the characteristics of the different types of courses required for our approach, we now consider how to facilitate its implementation. The two primary issues - each of which can have a major impact of the ease of implementation-involve timing and data selection.

\section{Phasing in the Tiers: Where to Start}

Clearly, Tier I courses require the least amount of faculty preparation, but also demand the greatest amount of faculty coordination. In most schools, each introductory functional course is taught by more than one faculty member, therefore a plan to introduce a stand-alone ERP lab into three or four introductory courses could require the consent of ten or twelve faculty. This may, indeed, be the greatest obstacle to the proposed approach.

The key here is to make the lab both as painless and as useful as possible. If it requires minimal preparation time on the part of the instructor, and also allows the instructor to capture students' interest with a "real-world" application, it is much more likely to win instructor approval. Still, the integration of ERP fully across the Tier I curriculum is likely to be a lengthy, if not time-consuming, process. If two or three different introductory courses can be selected for initial implementation at Tier I, this will provide a solid start for the curriculum-wide integration.

It is our experience that students exposed to ERP labs at Tier I will be interested in pursuing advanced ERP knowledge; it is therefore important to bring at least one Tier II course online simultaneously with the initial offerings in Tier I. Ideally, more than one course will be available at Tier II, but one initial offering is enough to "get the ERP ball rolling" and stimulate further faculty and student interest in ERP.

As noted above, the "real" ERP course(s) at Tier III requires significant faculty commitment and support; fortunately, it is not necessary to have this tier in place when ERP is first introduced into the curriculum. It is possible to imagine a fairly robust curriculum-wide ERP integration comprised solely of courses at Tiers I and II. Ultimately, however, an in- depth ERP course, such as a configuration course, provides an excellent capstone tying together the different functional applications in a single course.

\section{“Implicit” Integration: Using a Common Case Study}

Since students are going to be experiencing ERP from different functional vantage points, a key strategy to provide "implicit" integration across these different labs is to use a common company case study for every class. A student, for example, might first be exposed to ERP through a lab in an operations class; later in that same quarter, she might then see the same fictional company from a different viewpoint by working a lab exercise in an accounting class. Students return to the case repeatedly in increasingly greater depth, culminating in the Tier III class(es) where they configure the enterprise system for the fictional company.

There are an increasing number of prepared fictional company data sets provided by SAP AG for classroom use. Each company data set is preconfigured in a separate client that may be loaded by a University Alliance member for a particular class in a particular quarter. There is the IDES client, which is a demonstration client used by SAP for company sales demonstrations; this client has data from multiple fictional companies entered, thus enabling the SAP salesperson to demonstrate the wide-ranging functionality of SAP to potential customers. The advantage of the IDES data is that it includes the variety needed to demonstrate every possible functionality of SAP. This is also its greatest drawback for educational uses, as it is easy for novice users to lose themselves in the system.

Many universities have configured educationoriented clients that use much simpler examples, and SAP has made some of these available to University Alliance members. These fictional companies and their corresponding clients have been designed for ease of classroom use and student comprehension. Depending on the case study, they also have the added benefit of prepared exercises and presentation materials available from the SAP University Alliance website. Needless to say, these prepared materials serve as an excellent starting point for Tier I and Tier II course materials.

\section{THE THREE TIERS AT WWU}

Western Washington University joined the SAP University Alliance Program in 2004; prior to that instance, the use of ERP in the classroom had been 
restricted to a single operations planning and control class (the "original course"). The original course utilized a small-market ERP package to introduce students to ERP.

The instructor of the original course led the implementation of SAP at Western Washington University. While he found many faculty interested in the possibility of integrating some ERP elements into their courses, course development time was a consideration. For the first year of membership in the Alliance, the instructor and one MIS professor were the only instructors to incorporate SAP labs into their courses; the two courses involved were essentially "Tier II" courses, and enrollment was therefore restricted to operations management and management information systems majors. The labs were home-grown-which took considerable development time on the part of an extremely capable TA — and housed in an empty client.

After much faculty discussion regarding classroom needs and practical constraints, the key ERP instructors devised the three-tiered approach presented in this paper. The first decision was to scrap the highly customized lab and rely on the Fitter Snacker case study [8] and the corresponding client setup developed and maintained by Wagner at Western Michigan University; the client was preconfigured for classroom use and required minimal setup each quarter. Furthermore, prepared lab and teaching materials were readily available from the
University Alliance website. Designing the initial labs for the Tier I and Tier II courses primarily consisted of selecting from the initial documentation and reformatting. As instructors familiarized themselves with the Fitter Snacker materials and data, lab content was expanded upon and modified based on areas of instructor interest.

The past, present and near future of Western Washington University's ERP integration is shown below in Figure 2. The four courses with a blank background-three at Tier I and a "core" course at Tier II-were all introduced in the 2005-2006 academic year as the first phase of the tiered approach. Courses with a speckled backgroundanother core Tier II course and the Tier III coursewere either introduced or revised for the 2007-2008 academic year. Finally, discussions are currently ongoing with instructors of the courses with a hatched background; ERP integration is not likely to happen in these courses until 2008.

The focus on courses in operations management, management information systems, and accounting was not intended to slight the other disciplines; rather, it was decided that these three areas represented a critical minimal set of disciplines necessary for a solid education in ERP. While course material development can be minimized by following the guidelines proposed here, it is still not cost-free and key ERP personnel need to focus their efforts where it will do the most immediate good.

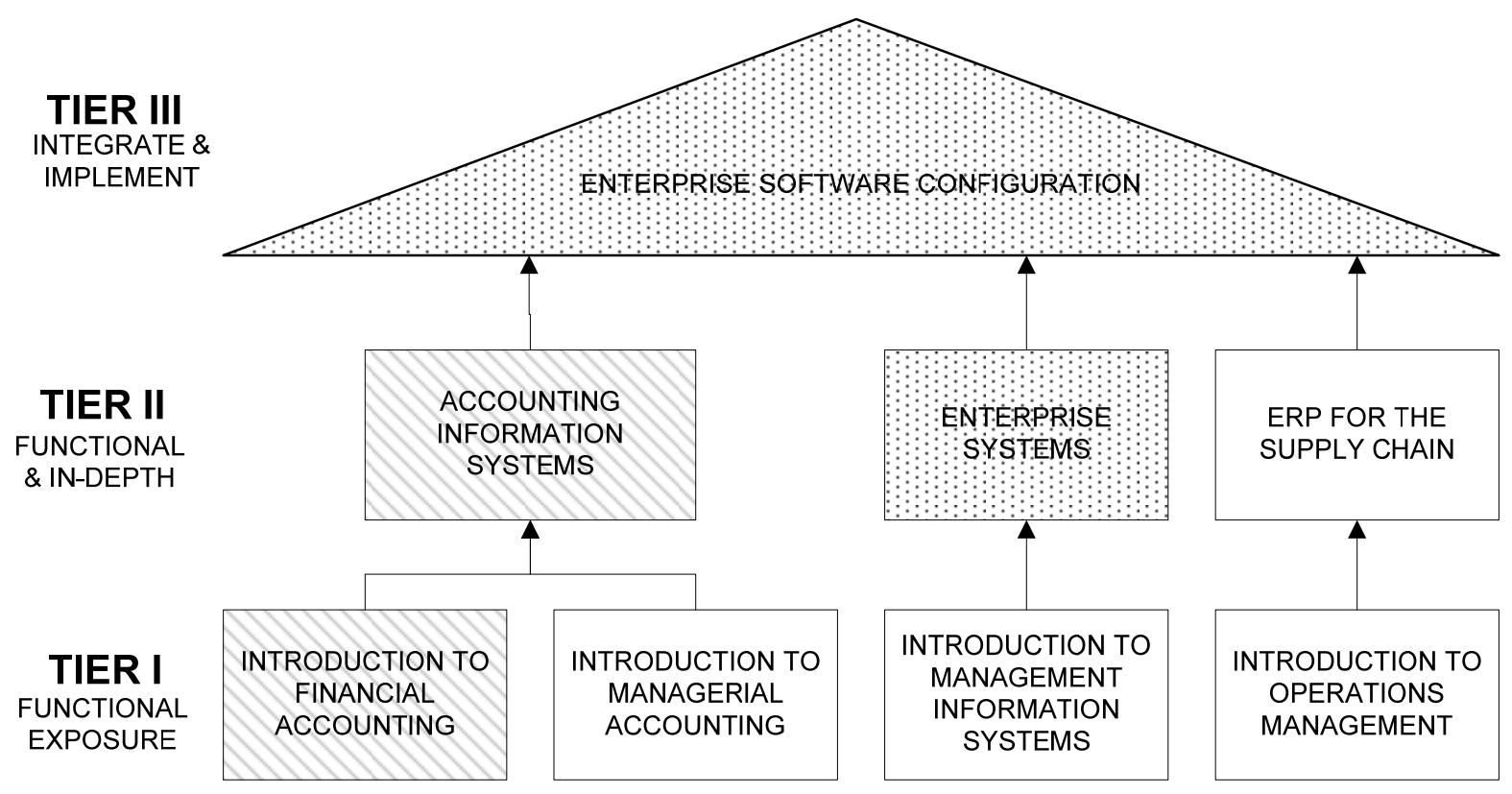

Figure 2. Tiered ERP Curriculum Implementation at Western Washington University 


\section{Example Labs}

To further illustrate the nature of the three tiers, the following section discusses a single course offering from each tier and the nature of the concomitant labs.

The one-session ERP lab for students enrolled in the introductory MIS course exemplifies the key elements of a Tier I lab. Referencing master data and transactions entered by a TA prior to the lab, students are introduced to basic ERP concepts as they proceed through the sales order process. The lab takes students from the initial entry of a sales order through order picking, shipping, invoicing and the receipt of payment from the customer. The lab emphasizes the integrative nature of ERP, as students see how the movement of goods and money affects the different functional areas of the fictional Fitter Snacker Company.

Since students are viewing rather than entering transactions, they are provided with a short list of questions they must answer prior to completion of the lab. The questions specifically reference the transactions they are viewing, thus ensuring that students spend the time and thought necessary to make the critical link between the mechanics of the lab and the conceptual material discussed earlier in the class.

The ERP for the Supply Chain class contains the first Tier II labs developed at Western Washington University. While the labs in this class do take "detours" to illustrate the impact of supply chain decisions on the other functional areas of the Fitter Snacker Company, the focus is on demonstrating how ERP helps integrate the different tasks within the supply chain function. Students taking this course have been exposed to two or three single-session Tier I labs earlier in their academic career, so they have basic conceptual and navigational awareness of ERP systems in general and SAP in particular.

As the course title suggests, this is a "core" Tier II class in which the content focuses on the use of enterprise systems to manage the supply chain; five of the twenty class meetings in the supply chain class are dedicated to ERP lab exercises. The labs focus on the creation of and planning for a new product in an existing product family. Students must enter all of the production and supply chain data for the new product and its components, forecast demand, plan production, accept customer orders and purchase raw materials. The focus, therefore, is on the supply chain planning cycle, which involves several different tasks within the supply chain function.
As with the Tier I labs, students are provided with a set of questions for each lab, although rather than being collected the questions are advertised as "likely exam questions" to ensure serious consideration. After each lab, an instructor checks the data to ensure that students are ready to move on to the next exercise. Finally, as a final project, each student must complete the planning cycle for another new product.

The Enterprise Software Configuration class is the sole Tier III class currently planned for Western Washington University. As its name suggests, this course possesses both breadth and depth, as students must configure the Fitter Snacker Company in SAP starting with a empty client. Most course sessions for this class involve a significant amount of lab work; a typical class period involves an overview and discussion of the day's topics, followed by time allocated for the day's lab exercise.

Unlike the Tier I and II labs based on the Fitter Snacker data but customized at WWU, the lab component of the configuration class was taken directly from materials developed by Bret Wagner for the SAP University Alliance. Even so, the preparation time for the class has been significant; there are innumerable ways for students to err in the configuration, and both the instructor and his or her TA need to be prepared to dedicate significant time to diagnosing student errors.

While the Tier III configuration class is a serious commitment, it has become an essential element of the ERP curriculum at WWU. Following the functional focus of the Tier II courses, it shifts the emphasis back to the integrative nature of ERP as students build the cross-functional information links into the enterprise systems of their fictional companies.

\section{Expanding ERP Offerings in the Curriculum}

Once a skeletal tiered curriculum is in place, interest generated by students and faculty will help further development. The instructor of a non-core Tier II course not included in Figure 2 above recently asked for help in developing a short ERP lab for his course; he had heard of its use in other classes, and realized that a lab could help him demonstrate a "real-world" application of a difficult topic. Needless to say, it is important to be able to provide timely assistancemost easily through the use of a TA searching for and modifying appropriate University Alliance materials - for such faculty requests. 
It should be noted that Western Washington University has been quite fortunate in the caliber of its TA support for ERP lab development; both individuals filling the TA position for the operations group over the past three years had significant work experience with enterprise software. This situation is unlikely to continue in the near future, but once the basic course framework is established it generates its own expertise. For example, a successful student from this year's configuration class is currently working with one of the instructors on developing additional accounting lab materials.

While the state of the current implementation may therefore seem modest, we nonetheless feel it is a solid starting point that quickly introduced students to the essentials of ERP and is readily expanded upon.

\section{CONCLUSIONS}

The authors have presented an ERP curriculum implementation approach that recognizes and exploits the different objectives of potential ERP-related courses. Course goals may range from simple exposure (Tier I) to cross-functional integration (Tier III); ERP content may similarly range from a simple display-only lab (Tier I) to the bulk of the course (Tier III). Focusing on an initial offering including mostly Tier I courses, coupled with one or two Tier II courses in the same functional areas, offers a relatively low-cost approach to quickly introducing both breadth and depth in ERP to the curriculum. Once established, this curricular framework offers a base which is readily scalable as faculty in additional functional areas are encouraged to join the ERP initiative.

\section{REFERENCES}

1. Becerra-Fernandez, I., Murphy, K., \& Simon, S. J. (2000). Integrating ERP in the business school curriculum. Communications of the ACM. 43(4), 39-41.

2. Corbitt, G. (Chair) (2003). Future directions of ERP in the classroom and in the real-world, panel discussion. 2003 Annual Meeting of the Decision Sciences Institute, Washington, DC.

3. Corbitt, G., \& Mensaching, J., (2000). Integrating SAP R/3 into a college of business curriculum: lessons learned. Issues in Information Technology and Management. I(4), 247-258.

4. Hayen, R. L., \& Andera, F. A., (2006). Analysis of enterprise software deployment in academic curricula. Issues in Information Systems. VII(1), 273-277.

5. Hayen, R. L., \& Andera, F. A., (2005). Investigation of the integration of SAP enterprise software in business curricula. Issues in Information Systems. VI(1), 107-113.

6. MacKinnon, R.J., \& MacKinnon, R.J., (2004). ERP in AACSB universities belonging to SAPUA. Issues in Information Systems. V(2), 605-611.

7. MacKinnon, R.J., Rogers, C., Kung, H.J, Gardiner, A., Whitworth, J., \& Williams, S. (2006). Creating an ERP emphasis in the IS curriculum. Issues in Information Systems. VII(1), 284-288.

8. Monk, E., \& Wagner, B., Concepts in Enterprise Resource Planning, $2^{\text {nd }}$ Edition. Thomson, 2006.

9. SAP AG (2001). What's New With the SAP Alliance Program in the US.

10. SAP AG (2004). SAP University Alliance Program: Curriculum Plan Guidelines.

11. Willems J. R. \& Bhuiyan, S., (2006). Implementing ERP software into business school curriculum: it is more common, less difficult and more important than you may think. Issues in Information Systems. VII(1), 278-283. 